\title{
Educación para el Siglo XXI. El desafío latinoamericano
}

Mario Waissbluth. Fondo de Cultura Económica. Santiago, 2018, 183 páginas. ISBN: 978- 956- 289- $173-8$.

El libro Educación para el Siglo XXI. El desafío latinoamericano fue escrito por Mario Waissbluth y publicado a mediados de 2018 por el Fondo de Cultura Económica. Debido a que desde la creación de Fundación 2020 el autor se ha posicionado como una de las voces más influyentes en la discusión sobre políticas educativas en Chile, la lectura de este texto resulta imprescindible para quienes estén interesados en aportar al debate educativo y contribuir a mejorar la calidad y la equidad de la educación en Latinoamérica.

En el capítulo I, el autor advierte que las decisiones que se tomen hoy en materia de política pública educativa impactarán a lo largo del siglo XXII, lo cual requiere enfrentar con urgencia los deficientes desempeños educativos que presentan los niños, jóvenes y adultos de la Región. En reiteradas oportunidades el relato recuerda que, pese a los avances en cobertura, los estudiantes y adultos no comprenden lo que leen ni pueden realizar operaciones aritméticas sencillas.

Esta alarmante problemática es situada en perspectiva histórica en el capítulo II, donde se alude al origen de los Estados Nación latinoamericanos y a su constitución a partir de procesos coloniales europeos. Se afirma que la inequidad, la pobreza y la segregación que caracterizan nuestros sistemas educativos, así como sus débiles resultados académicos, tienen sus orígenes en las instituciones coloniales y en la posterior mezquindad de las élites dominantes. A juicio del autor, la economía colonial monopólica y el peso de la inquisición no habrían posibilitado el desarrollo científico ni productivo local, como sí sucedió en otras colonias.

Los posteriores procesos independentistas tampoco habrían alterado mayormente la estructura social imperante durante la Colonia, perpetuando la desigualdad, la pobreza y la explotación en las nuevas repúblicas. Por otro lado, la incipiente industrialización de mediados del siglo XX no habría prosperado por no haberse sustentado en educación y desarrollo científico. Así, se habría pasado de "una forma rapaz de mercantilismo rentista", como fue la Colonia, al "vicio histórico de la élite latinoamericana: enriquecerse rápido, aprovechando prebendas y sin ofrecer una educación sólida a la mayoría” (p. 35). Frente a la profundidad histórica del problema, el autor enfatiza la necesidad de comprender el sistema educativo desde la interacción de múltiples y variados factores, incorporando enfoques sistémicos e intersectoriales, así como soluciones flexibles y adaptativas.

Una vez aclaradas las raíces históricas del problema, en el capítulo III Waissbluth expone las fallas de las políticas educativas en nuestro continente desde algunas categorías conceptuales centrales. El autor sostiene que las políticas no han evolucionado con criterios científicos, sino que han respondido a urgencias coyunturales, siendo muchas veces concebidas 
desde veredas ideológicas y promovidas por movimientos ciudadanos, careciendo de visiones y consensos a largo plazo. Asimismo, critica una "industrialización y estandarización de la educación" que privilegia ciertos contenidos curriculares y el uso de tests estandarizados como herramientas de medición. En ese sentido, propone una concepción más compleja de calidad y afirma que, además de los conocimientos en lectura y matemáticas, el currículum escolar debe incluir el desarrollo de habilidades, actitudes y valores.

En el capítulo IV, denominado "El rescate de los niños y jóvenes como prerrequisito", el autor alude a la vulneración de derechos de millones de niños y jóvenes, calificándola como "el dolor de América Latina”. Se trataría de un "problema retorcido" por tratarse de un fenómeno que tiene múltiples causas, requisitos y condiciones contradictorias y cambiantes, así como una gran diversidad de consecuencias y ramificaciones. Waissbluth denuncia que niños y jóvenes son víctimas de prácticas de violencia intrafamiliar, inequidad social y educativa, a lo que se suma una educación inicial de baja cobertura y una escolaridad poco motivadora. A su vez, ellos presentan problemas de salud mental y creciente consumo de alcohol y drogas. Frente a este escenario, y a un modelo económico angustiante, cabría esperar que esos niños arrastren importantes trastornos hasta la adultez, lo que a su vez podría redundar en una inadecuada protección de la infancia en las próximas generaciones. Así, el círculo vicioso sería de hierro.

En los capítulos V y VI el autor se atreve a ofrecer propuestas para romper esta cadena, entendiendo que el problema no puede ser enfrentado con soluciones aisladas, sino de manera integral y sistémica. En ese contexto, destaca la relevancia de la Educación Inicial respecto de los demás niveles educativos, señalando el enorme potencial de los primeros cinco años de vida en el desarrollo lingüístico y cognitivo, así como en habilidades socioemocionales, morales y de autocontrol. El autor denuncia escasa cobertura, inequidad de acceso a la Educación Inicial entre ricos y pobres, y débil calidad de los programas educacionales en primera infancia. Además, señala como razones fundamentales la existencia de débiles procesos de reclutamiento y formación profesional en educación parvularia y un gasto insuficiente en Educación Inicial, siendo tres veces menor que el destinado a Educación Escolar. Waissbluth enfatiza que esta relación debiese ser inversa, dado que la rentabilidad social de un dólar invertido en infancia temprana sería entre seis y ocho veces mayor que en Educación Superior o en capacitación laboral.

En relación con la Educación Escolar, el texto compara el desempeño de los países de la Región en tests estandarizados, reconociendo una amplia heterogeneidad que va desde países con buenos resultados, como Cuba, a países con resultados altamente deficientes, como República Dominicana. El autor sostiene que la segregación a nivel del sistema escolar reproduce las desigualdades de la sociedad y opera desde niveles iniciales. Como consecuencia, no debiera sorprender que los niños más pobres acarreen un retraso de entre 1,5 y 2,5 años de aprendizaje respecto a sus pares más ricos. Esto se vería agravado por prácticas que segregan a los niños según sus habilidades académicas al interior de las escuelas y por una 
baja cobertura educacional entre niños y jóvenes discapacitados, alcanzando solo al 30\% de este grupo, tradicionalmente postergado.

En el capítulo VI Waissbluth busca desnaturalizar algunos mitos en materia educativa, los que se habrían ido instalando pese a no sustentarse en evidencia empírica. La extensión de la jornada escolar y la incorporación irreflexiva de tecnología en el aula, serían, a juicio del autor, dos ejemplos del divorcio entre las decisiones de la burocracia y el desarrollo de la investigación en educación. El texto propone recomendaciones de corto y largo plazo, basadas en evidencia científica, para abordar los problemas de la Educación Escolar.

El libro finaliza con un capítulo sobre recursos financieros donde se enfatiza la necesidad de aumentar progresivamente la inversión en educación en los países latinoamericanos. El autor es directo al plantear que el aumento del gasto se lograría si los sectores más acomodados de la Región decidieran "meterse la mano al bolsillo". Así, Waissbluth solicita un "pequeño acto de generosidad" para que los más poderosos destinen parte de sus ingresos a asegurar el futuro de la Región.

Con un planteamiento fluido y un tono persuasivo, el autor pone acento sobre las principales dificultades que enfrenta América Latina en materia educativa. La estructura del ensayo es convincente, permitiendo generar incomodidad y alarma hasta en el lector menos sensibilizado respecto de esta temática. La sensación de urgencia que generan sus diagnósticos y propuestas debería ser un llamado de atención para todos quienes puedan hacer algo para contribuir con esta tarea.

Waissbluth realiza un esfuerzo destacable al desmenuzar las problemáticas y definir urgencias, sin embargo, deja algunos espacios vacíos que resultan difíciles de comprender. El primero, y más complejo de todos, es la escasa mención a la historia reciente de los países latinoamericanos, sus dictaduras y a sus transversales políticas neoliberales en la década de los ochenta y noventa ${ }^{1}$. A pesar de coincidir en la profunda historicidad colonial que el autor otorga a la desigualdad y pobreza de la Región, intentar comprender la desigualdad del sistema educativo sin abordar la instalación forzada del neoliberalismo en los distintos países, genera al menos desconfianza. Por ejemplo, aludir a la mala calidad de los profesores en Chile y a las problemáticas sociales que viven los niños y jóvenes, sin aludir a la disminución de derechos sociales, la desregulación en la formación del profesorado y la desmunicipalización², resulta un despropósito.

1 French-Davis, R., \& Machinea, J. L. (2007). Economic Growth with Equity. New York: Palgrave Macmillan. Oliva, M. A. (2008). Política educativa y profundización de la desigualdad en Chile. Estudios pedagógicos (Valdivia), 34(2). https://doi.org/10.4067/S0718-07052008000200013

Rojas, L. (Ed.). (2015). Neoliberalismo en América Latina. Asunción, Paraguay: CLACSO.

2 García-Huidobro, J. E. (2007). Desigualdad educativa y segmentación del sistema escolar. Consideraciones a partir del caso chileno. Pensamiento Educativo, 40, 65-85.

Puga, I. (2011). Escuela y estratificación social en Chile: ¿cuál es el rol de la municipalización y la educación particular subvencionada en la reproducción de la desigualdad social? Estudios pedagógicos (Valdivia), 37(2), 213-232. 
Waissbluth es enérgico al enfatizar que la Educación Inicial debe ser priorizada respecto de los otros niveles educativos. Diversas evidencias corroboran el valor predictivo de este nivel educativo en las siguientes etapas de la vida de las personas. Sin embargo, los argumentos planteados podrían ser cuestionados hasta cierto punto, si se considera la amplia literatura relativa al alto valor predictivo de la educación de los padres en el desempeño de sus hijos. En efecto, diversa literatura aborda las ventajas comparativas que tienen los hijos de profesionales respecto de los hijos de no profesionales ${ }^{3}$. Se podría argumentar entonces, que invertir en Educación Superior podría ser una estrategia previa a la Educación Inicial, y que podría tener efectos equivalentes. La reflexión por supuesto resulta aventurada, pero el argumento sobre la educación de los padres es escasamente planteado en el ensayo y, sin cuestionar la importancia de la inversión en primera infancia, podría ser un elemento relevante a considerar para los fines propuestos. La pregunta redunda en la tradicional disyuntiva respecto de qué viene antes... ¿el huevo o la gallina?

En otro orden de cosas, cabe señalar que el ensayo tiene el mérito de aportar una síntesis sobre el estado de la educación en Latinoamérica, sin embargo, dadas las diferencias extremas que se observan entre algunos países de la Región -que Waissbluth corrobora con una buena cantidad de datos-, resulta arriesgado generalizar e ingenuo intentar capturar esas particularidades en una sola gran mirada global. Por otra parte, dado el sesgo de origen del autor, la realidad chilena se ve sobre-representada respecto de los demás países, lo cual podría resultar hasta contraproducente, considerando que el propósito de la publicación es convocar a un debate a nivel regional.

Pero la mayor preocupación sobre este debate surge en las últimas páginas del libro, cuando Waissbluth, en un acto de esperanza, que se acerca a la ingenuidad, plantea que la posibilidad de contar con los recursos financieros para el cambio educativo se juega en "un pequeño acto de generosidad" de la élite política y económica. Si la esperanza sobre el futuro de nuestras naciones está puesta en ese acto de generosidad, la frustración, la inequidad y la tristeza probablemente seguirán inundando nuestra América Latina.

\author{
Úrsula Bravo, \\ Pontificia Universidad Católica de Chile \\ URSULA.BRAVO@UC.CL
}

\author{
NiCOLE ABRicot, \\ Universidad de SANTiago de Chile \\ NICOLE.ABRICOT@USACH.CL
}

3 Bourdieu, P., \& Passeron, J. C. (1979). The Inheritors: French Students and their Relations to Culture. Chicago: The University of Chicago Press.

Rothstein, R. (2004). Class and Schools. New York, NY: Teachers College Columbia University. 